\title{
Co-Localization of Alpha1-Adrenoceptors and GPR55: A Novel Prostate Cancer Paradigm?
}

\author{
Kalyani Chimajirao Patil, Laura McPherson, Craig James Daly \\ College of Medical, Veterinary \& Life Sciences, School of Life Sciences, University of Glasgow, Glasgow, UK \\ Email: Craig.Daly@Glasgow.ac.uk
}

Received 11 February 2015; accepted 2 April 2015; published 3 April 2015

Copyright (C) 2015 by authors and Scientific Research Publishing Inc.

This work is licensed under the Creative Commons Attribution International License (CC BY). http://creativecommons.org/licenses/by/4.0/

c) (7) Open Access

\begin{abstract}
$\alpha_{1}$-adrenoceptors ( $\alpha_{1}$-ARs) and "cannabinoid-like" G Protein Coupled Receptor 55 (GPR55) belong to the G-protein coupled receptor (GPCR) family and play a crucial role in regulating prostate function. Although physical and functional interactions between the cannabinoid and adrenergic systems have been reported, analysis of functional interactions between $\alpha_{1}$-AR and GPR55 in normal and neoplastic prostate has not been reported. Since GPR55 levels are high in rodent adrenal gland, we propose a function link between the adrenergic system and GPR55 receptor. Confocal Laser Scanning Microscopy (CLSM) was employed to examine the endogenous $\alpha_{1}$-AR and GPR55 expression and their co-localization, expressed as fluorescence, in vitro in human androgen-insensitive PC-3 and androgen-sensitive LNCaP prostatic carcinoma cell lines, using the fluorescent ligands-Syto 62 (nuclear stain), BODIPY FL-Prazosin (QAPB; fluorescent quinazoline $\alpha_{1^{-}}$ AR ligand) and Tocriflour (T1117; a novel fluorescent diarylpyrazole cannabinoid/GPR55 ligand). Fluorescent ligand binding in untreated PC-3 cells and LNCaP cells and spheroids showed heterogeneous expression of both $\alpha_{1}$-ARs and GPR55. A small proportion of cells had both $\alpha_{1}$-ARs and GPR55 in relatively equal numbers indicating a degree of co-localization. Co-localization of fluorescent ligand binding exhibited a stronger correlation in LNCaP $(0.87)$ as compared to PC-3 (0.63) cells. Upregulation of $\alpha_{1}$-AR was observed in PC-3 cells following chronic doxazosin incubation. Robust T1117 binding, suggestive of GPR55 upregulation, was also observed in these cells. The presence of subtype-rich cells with a degree of co-localization between $\alpha_{1}$-ARs and GPR55 indicates a possibility for dimerisation or functional interaction and a new paradigm for functional synergism in which interactions may be either between cells or involve converging intracellular signaling processes.
\end{abstract}

\section{Keywords}

Prostate, $\alpha_{1}$-Adrenoceptor, GPR55, Doxazosin 


\section{Introduction}

Prostate cancer (PCa) is the most common non-cutaneous male cancer and the second highest cause of cancerrelated deaths in Western society [1]. PCa mortality results from bone and lymph node metastasis and the progression from androgen-dependent to androgen-independent PCa cell growth [2]. The disease is heterogeneous in terms of grade, oncogene/tumor suppressor gene expression, genetics, and its molecular, cellular and hormonal profile is complex [1]. These alterations and heterogeneity result in the failure of androgen ablation therapy and chemotherapy, which are major therapeutic modalities for advanced PCa [3]. Therefore, considerable efforts are directed towards developing treatment strategies targeting receptors that are a part of the molecular circuitry controlling tumor growth.

\subsection{Adrenoceptor}

In PCa, the involvement of a wide range of G-protein coupled receptors (GPCRs) has been described [4]. The $\alpha_{1}$-adrenoceptors $\left(\alpha_{1}\right.$-ARs) are of particular interest given their role in prostate function, and use as a therapeutic target. A recent comprehensive review of prostatic $\alpha_{1}$-ARs outlines the complex signaling pathways and additional GPCRs that this receptor can interact with [5]. Currently, the recognized subtypes of $\alpha_{1}$-ARs are $\alpha_{1 \mathrm{~A}}, \alpha_{1 \mathrm{~B}}$, $\alpha_{1 \mathrm{D}}$ [6]. $\alpha_{1 \mathrm{~A}}$-AR subtypes are the main prostate receptors and predominate in prostate stroma. $\alpha_{1 \mathrm{D}}$-AR subtype is also found in the stroma whereas $\alpha_{1 \mathrm{~B}}$-AR is mainly found in the epithelium [7]. Functional studies suggest a predominance of $\alpha_{1}$-ARs which have low affinity for the quinazoline drug, Prazosin, and these have been classed as $\alpha_{1 \mathrm{~L}}$-AR, a functional phenotype of $\alpha_{1 \mathrm{~A}}$-adrenoceptor, in mouse prostate [8].

The role of $\alpha_{1}$-ARs in human prostate is undisputed and therefore, is the most commonly targeted GPCR in the prostate. The $\alpha_{1}$-AR antagonists belonging to quinazoline family of drugs have therapeutic benefit in PCa as they induce apoptosis in the epithelial and smooth muscle cells of the prostate without affecting their proliferative capacity [9] [10]. Therapeutically, quinazolines decrease the incidence of PCa by 31.7\% [11]. Evidence highlights the emerging therapeutic significance of two quinazoline drugs, Terazosin and Doxazosin as antitumor agents in PCa therapy. Doxazosin mesylate (brand name: Cardura), a subtype non-selective $\alpha_{1}$-adrenoceptor antagonist, promotes smooth muscle relaxation. Doxazosin has also been documented to induce apoptosis and anoikis in PCa cells, both in vitro and in vivo [12]. The apoptotic activity of this quinazoline antagonist is independent of: 1) ability to antagonize $\alpha_{1}$-AR; and 2) the hormone sensitivity of cells (i.e. androgen dependency) but dependent upon number and distribution of smooth muscle cells in the tissue [9]. It induces apoptosis by a) increasing caspase-3 activity in a concentration and time dependent manner which activate intracellular cascade promoting anoikis and subsequently, apoptosis; b) cleavage of focal adhesion kinases (FAK), a non-receptor tyrosine kinase mediating cell proliferation and migration, by caspases and c) decreasing Akt phosphorylation which has been shown to interfere with the apoptotic action of doxazosin [13] [14].

\subsection{Endocannabinoids}

Several studies have evaluated the role of the endocannabinoid system, consisting of classic cannabinoid receptors, CB1 and CB2, two endogenous ligands (anandamide and 2-arachidonoylglycerol) and several enzymes required in their production and degradation, in different PCa tissue/cell lines [15]. High CB1 receptor immunoreactivity score in PCa tissue was found to be associated with PCa severity and outcome [16]. Also, CB2 receptor expression was demonstrated in multiple PCacell lines (PC-3, DU-145, LNCaP, CWR22Rv1 and CA-HPV10) [17]-[21]. However, role of a putative cannabinoid receptor GPR55, a 319-amino acid multi-pass membrane protein phylogenetically distinct from CB1 and CB2, in tumor progression suggests its importance as a possible cancer biomarker. High levels of GPR55 have been associated with aggressive cancers [22] and tumor angiogenesis [23].

We have previously shown co-localization between T1117, a fluorescent form of the cannabinoid CB1 receptor antagonist AM251, which showed binding affinity for GPR55 [24] and BODIPY FL-Prazosin (QAPB), a fluorescent ligand for all $\alpha_{1}$-AR subtypes [25] in vascular tissue indicating their possible interaction in the cardiovascular system. Since tissue distribution of GPR55 overlaps significantly with $\alpha_{1}$-AR in prostate, and GPR55 shares similar pharmacology with the classical cannabinoid (CB1) receptors [26], we investigated the degree of heterogeneity and possibility of interaction between $\alpha_{1}$-AR and GPR55 by examining their distribution and co-localization in vitro using two commonly used prostate carcinoma cell lines; LNCaP and PC-3. The 
LNCaP and PC-3 cell lines were selected as they display appropriate cellular characteristics and are widely used to model androgen-dependent early stage PCa and androgen-independent later refractory stage disease, respectively. Importantly, our findings provide preliminary evidence of co-localization and possible interaction between $\alpha_{1}$-AR and GPR55 and its physiological importance in neoplastic prostatic cell in vitro which has never been studied prior to this study.

\section{Materials and Methods}

\subsection{Materials}

Stock concentrations of fluorescent ligands were dissolved in dimethyl sulphoxide (DMSO), and diluted in distilled water as required. Ligands were obtained from the following sources: BODIPY FL-Prazosin (QAPB) and Syto 62 from Invitrogen (Invitrogen Ltd., Paisley, UK); Tocrifluor T1117 (N-(piperidin-1-yl)-5-(4-(4-(3-(5carboxamidotetramethylrhodaminyl) propyl)) phenyl)-1-(2,4-dicholrophenyl)-4-methyl-1H pyrazole-3-carboxamide) from Tocris (Bristol, UK) and Doxazosin from Pfizer (Sandwich, UK).

\subsection{Cell Culture}

The human androgen-insensitive, PC-3 (ATCC: CRL-1435) and androgen-sensitive, LNCaP (ATCC: CRL-1740) prostatic carcinoma cell lines were obtained from American Type Culture Collection repository. Cells were cultured in the appropriate media recommended by the supplier supplemented with 10\% Fetal Bovine Serum (FBS), Penicillin-Streptomycin (Pen-Strep) and L-Glutamine in a humidified incubator at $37^{\circ} \mathrm{C}, 95 \% \mathrm{O}_{2}$ and $5 \% \mathrm{CO}_{2}$ until confluent. Upon attaining confluence, the cells were trypsinized and rinsed in media and PBS. Subsequently, cells were re-suspended and plated to glass coverslips 24 hours before use.

\subsection{Confocal Analysis}

BODIPY FL-Prazosin (QAPB, $0.1 \mu \mathrm{M})$ and Tocriflour (T1117, $0.1 \mu \mathrm{M})$ were applied in combination to determine the receptor expression and co-localization in a) control untreated PC-3 and LNCaP cells and LNCaPderived spheroids (24 hours) and b) PC-3 cells under chronic doxazosin treatment (6 weeks; $1 \mu \mathrm{M})$ allowed to regrow in drug-free media (2 weeks). Incubation media also included a fluorescent nuclear stain Syto 62 (1 $\mu \mathrm{g} / \mathrm{ml})$. Cell images are representative of at least three independent experiments in all cases.

\subsection{Microscopic Examination}

Cells were imaged using a Bio-Rad Radiance 2100 Confocal Laser Scanning Microscope (CLSM) using either an oil immersion lens $20 \times$ (NA 0.75 ) or $40 \times$ objective (NA 1.0). The CLSM was fitted with an argon ion, Green Helium Neon (HeNe) and red diode laser. In all comparative studies, laser intensity and photomultiplier tube (PMT) settings were identical. Fluorescent ligands were imaged as follows: QAPB (ex 488 nm, em $515 \mathrm{~nm}$ ); T1117 (ex 543 nm, em 590 nm) and Syto 62 (ex 637 nm, em 660 nm). Multi-channel images are displayed as merged channels. Detailed analysis methods have previously been published [27].

\subsection{Data Analysis}

Data was collected, recorded and quantified using ImageJ 1.44p. Co-localization was quantified using the JACoP plugin for ImageJ and expressed as a Pearsons Correlation between two fluorophores generated from $\mathrm{n}=4$ for PC-3 cells and n = 5 for LNCaP cells. Graphs were drawn using GraphPad PRISM 5.0. Data was expressed as mean \pm SEM (Standard Error Mean) of at least 3 independent experiments. Statistical tests such as students T-tests were carried out and significance was defined as $\mathrm{P}<0.05$.

\section{Results}

\subsection{Co-Localization of Adrenergic and Cannabinoid Binding Sites in Prostate Cancer Cells}

Figure 1 shows the binding pattern of QAPB and T1117 in PC-3 and LNCaP cells (control). In control cell population, heterogeneity extended to the expression of both $\alpha_{1}$-ARs and GPR55. A spectrum of phenotypes was observed within the cell population, from those expressing predominantly $\alpha_{1}$-AR to those harboring predomi- 

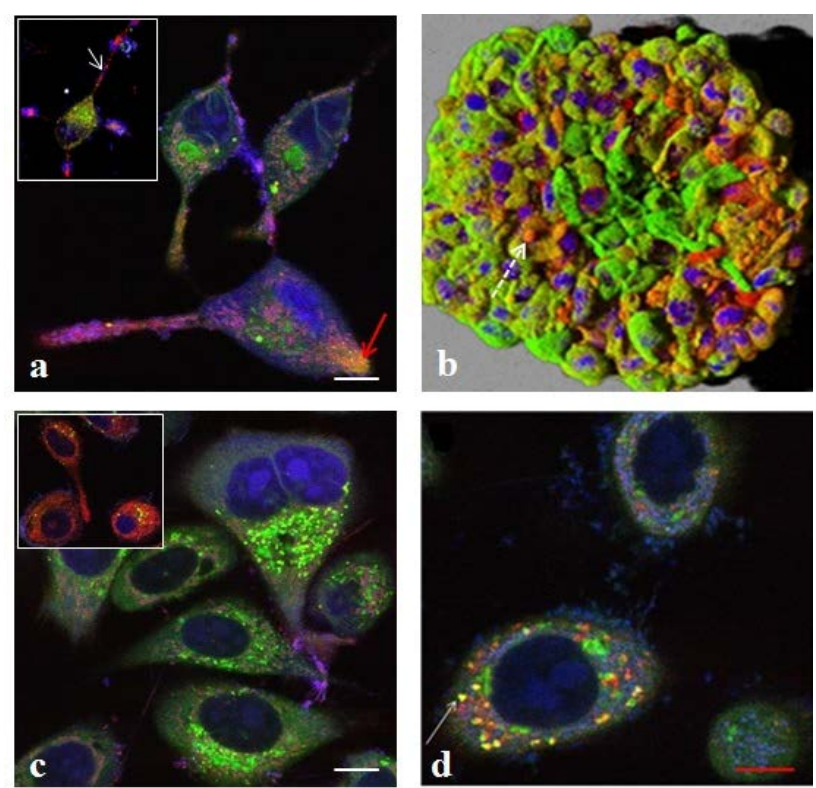

Figure 1. Fluorescent ligand binding and co-localization in PC-3 and LNCaP cells and LNCaP-derived spheroids. (a) Confocal scan of LNCaP cells after incubation with QAPB and fluorescent cannabinoid ligand T1117 (both $0.1 \mu \mathrm{M}$ ) showing a combination of cells expressing $\alpha_{1}$-AR (green), GPR55 (red) or both in relatively equal amounts (yellow; red arrow). Inset: LNCaP cells showing high GPR55 concentration (red fluorescence; white arrow) within the cell processes; (b) LNCaP-derived spheroids showing similar heterogeneity in receptor expression with certain areas showing co-localization of $\alpha_{1}$-AR and GPR55 (dotted arrow); (c) Confocal images of PC-3 cells showing $\alpha_{1}$-AR positive cells (QAPB binding-induced green fluorescence) and GPR55 positive cells (T1117 binding-induced red fluorescence) (inset); (d) Arrow indicates overlapping regions (yellow) of receptor location suggesting a degree of co-localization of $\alpha_{1}$-ARs and GPR55. Nuclei stained with Syto $62(1 \mu \mathrm{g} / \mathrm{ml})$. Calibration bar ((a) and (c)) indicates 20 microns and for (d) indicates 15 microns.

nantly GPR55 (Figure 1(c)). Importantly, it was apparent that PC-3 cells do not simply express $\alpha_{1}$-ARs and GPR55 in equal proportions. A small proportion of cells had both $\alpha_{1}$-ARs and GPR55 in relatively equal numbers reflected by the yellow fluorescence indicating a degree of co-localization of QAPB and T1117 (Figure 1(d)). LNCaP cells (in some but not all) (Figure 1(a)) and spheroids (Figure 1(b)) also demonstrated clear degree of co-localization between $\alpha_{1}$-AR and GPR55. Co-localization (correlation analysis) of QAPB and T1117 binding revealed a stronger correlation in LNCaP $(0.87 \pm 0.03)$ cells vs PC-3 $(0.63 \pm 0.02)$ cells. Interestingly, T1117 binding was always associated with the long processes and cell tips of LNCaP cells (Figure 1(a)).

\subsection{Chronic Doxazosin Treatment Elicits Upregulation of Intracellular $\alpha_{1}$-AR and GPR55 Expression, Accompanied by Stimulated Growth of PC-3 Cells}

The even distribution of binding sites, in certain areas and apparent co-localization of QAPB and T1117 in control PC-3 cells suggested co-expression and possibility of strong physical/functional association between the two receptors. To determine whether the functional antagonism of $\alpha_{1}$-AR might result in altered GPR55 expression, ligand binding studies were performed in cells that received $1 \mu \mathrm{M}$ doxazosin treatment for 6 weeks and returned to drug-free media for 2 weeks. The QAPB and T1117-binding induced fluorescence were determined in doxazosin-treated PC-3 cells normalized against fluorescence seen in untreated cells. Chronic administration of doxazosin resulted in significant $(\mathrm{P}<0.05)$ increase in the fluorescence induced by QAPB binding suggesting upregulation in $\alpha_{1}$-AR (Figure 2(a)). T1117-binding induced fluorescence was significantly higher $(\mathrm{P}<0.01)$ following chronic treatment with the $\alpha_{1}$-antagonist (Figure 2(b)). Sample cells are shown for comparison (Figure 2(c), Figure 2(d)). 

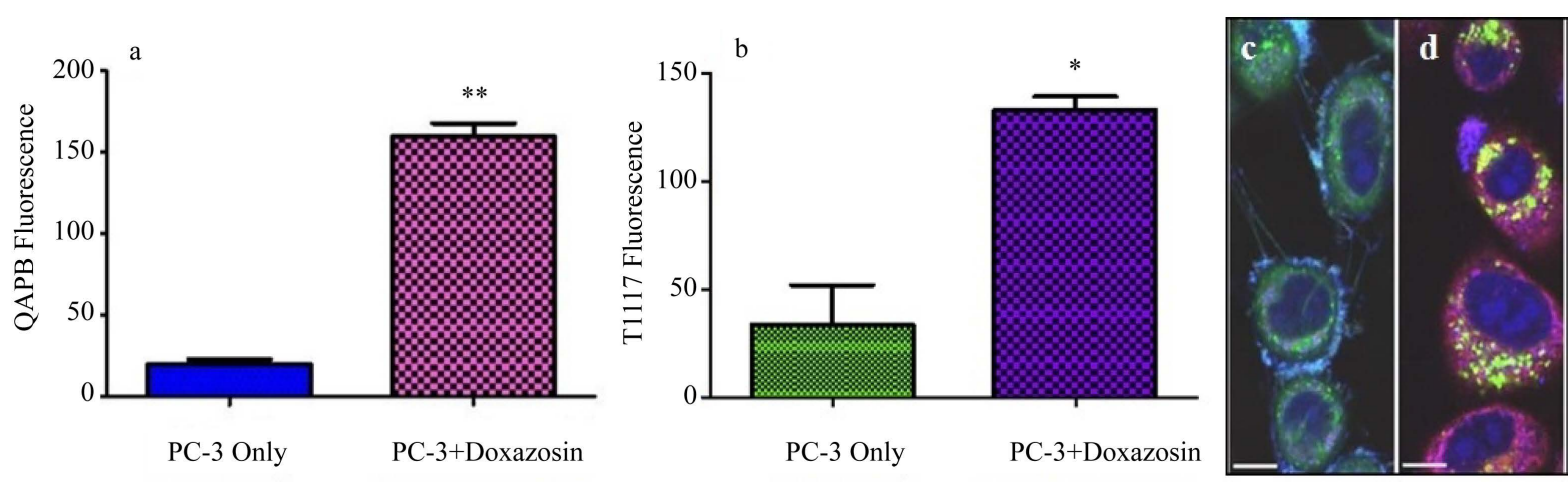

Figure 2. Chronic doxazosin treatment causes upregulation of $\alpha_{1}$-AR and GPR55 expression. (a) Quantitative fluorescence measurement of QAPB binding in the presence and absence of doxazosin; (b) Analysis of GPR55 expression determined by T1117 fluorescence in PC-3 cells showing upregulation after chronic doxazosin treatment. As a positive control, PC-3 cells showing normal growth mechanisms were used. Results are expressed as mean \pm SEM. ${ }^{*} \mathrm{P}<0.05,{ }^{* *} \mathrm{P}<0.01$. (c)-(d) Confocal images of PC-3 cells before (c) and after (d) chronic doxazosin treatment ( $1 \mu \mathrm{M}, 6$ weeks). A predominance of intracellular GPR55 was observed in response to chronic administration of doxazosin. Each image is a representative of those generated from three independent experiments. (Scale bar 20 microns).

\section{Discussion}

In recent years, a wealth of information describing the molecular mechanics of GPCR cycle involving agonist activation, internalization, downregulation and sequestration have been obtained. In addition, significant amount of evidence has highlighted the importance of GPCR dimerisation and co-localization that may alter receptor function, pharmacology or regulatory properties [28]. However, heterodimerisation dynamics and its generality in controlling receptor expression are not widely explored. Fluorescent ligand binding in vitro in PC-3 and LNCaP cells and LNCaP-derived spheroids demonstrated clear degree of co-localization (in some but not all cells) between $\alpha_{1}$-AR and GPR55. Homodimerisation and more selective heterodimerisation between individual $\alpha_{1}$-AR subtypes have been reported [29]. Assays showing functional interactions between cannabinoid and adrenoceptor ligands have, in fact, confirmed that adrenoceptor heterodimerisation may extend beyond $\alpha \alpha$ and $\alpha \beta$ interactions [24]. Although the resolution of current fluorescence-based study was insufficient to confirm the existence of $\alpha_{1}$-AR and GPR55 heterodimer, it does indicate their co-localization which is a pre-requisite of dimerization. In addition, evidence from recent molecular pharmacological studies has shown that co-expressed receptors can interact [26] [30] [31]. It can be hypothesized that co-localized $\alpha_{1}$-ARs and cannabinoid together potentiate the action of neurotransmitters in the prostate since the autonomic nervous system plays an important role in prostatic functions [32]. The co-localization of $\alpha_{1}$-ARs and GPR55 suggest a new paradigm for synergism in which interactions may be either between cells or involve converging intracellular signaling processes.

In PCa cells, fluorescent ligand binding studies showed binding sites for both T1117 and QAPB in different cellular locations (Figure 1). The binding of QAPB appeared to be more punctuate, both on the cell surface and intracellularly whereas binding sites for T1117 were more diffuse as seen earlier from the studies on vascular endothelium [24]. This pattern of binding allowed the classification of "subtype-rich" cells which could be classed as either expressing predominantly $\alpha_{1}$-AR or predominantly GPR55. The presence of 'subtype-rich' cells was also observed in PC-3 cells. The significance of this is currently unknown, but it suggests that a subpopulation of cells have a preferred receptor expression profile in respect of GPCR's.

Upregulation of intracellular $\alpha_{1}$-AR observed in PC-3 cells following removal of chronic $\alpha_{1}$-AR antagonism can be considered an adaptive response to chronic administration of doxazosin. This adaptive change may manifest as withdrawal response after long-term $\alpha_{1}$-AR antagonist use and can explain " $\alpha_{1}$-AR blocker withdrawal syndrome" as an aftermath of chronic stimulation of $\alpha_{1}$-AR. Aarons et al. (1980) have already reported this common outcome of an adaptive response to long-term $\beta$-AR antagonist use via upregulation of tissue $\beta$-ARs [33]. Although chronic doxazosin treatment has shown to alter $\alpha_{1}$-AR properties in rat prostate [34] [35], to our knowledge, there is no report of withdrawal response, via $\alpha_{1}$-AR upregulation, due to chronic administration of doxazosin in PCa cells.

In the present study, novel interaction between $\alpha_{1}$-AR and GPR55 was identified in vitro in control untreated 
and doxazosin-treated PC-3 cells. The apparently high expression of intracellular $\alpha_{1}$-AR in PC-3 cells showed that chronic doxazosin-induced response had an $\alpha_{1}$-AR component. This was expected; intriguingly, robust intracellular T1117 binding-fluorescence suggestive of GPR55 upregulation was also observed in these cells. This suggests that co-expression of $\alpha_{1}$-AR tempered the activity of GPR55 resulting in a dramatic increase in its intracellular expression in heterologous cells. It is possible that functional and perhaps physical association with $\alpha_{1}$-AR leads to changes in the localization of GPR55 to "active" areas in the intracellular compartment of a cell enriched with signaling molecules. The pre-requisite of this event is that the two receptors should be in close proximity, influencing their ability to transduce signals. Our co-localization study supports such a notion. In addition, our observation that PC-3 cells, high in GPR55, grow at a furious rate when returned to drug-free media (data not shown) supports our hypothesis that in a clinical setting, removal of $\alpha_{1}$-antagonism and the resultant stimulation of $\alpha_{1}$-AR may allow lysophosphotidylinositol (LPI), an endogenous natural ligand for GPR55 synthesized intracellularly from membrane phosphoinositols by phospholipase A2 (PLA2), formation via activation of PLA(2) to stimulate GPR55-mediated accelerated proliferation. A link between $\alpha_{1}$-AR stimulation and activation of PLA(2) has been reported [36] and if this could be demonstrated in prostatic smooth muscle then we would have a direct link between $\alpha_{1}$-AR stimulation and LPI production. The growth aspect is further substantiated by our observation of high levels of T1117 binding sites in the long processes of LNCaP cells.

It therefore is plausible that complex functional interaction between $\alpha_{1}$-AR and GPR55 exist whereby $\alpha_{1}$-AR antagonism directly affects GPR55 functionality by overexpression after chronic doxazosin treatment to support tumorigenesis by promoting cell growth and drug resistance. Therefore, the $\alpha_{1}$-ARs $\backslash$ GPR55 ratio could identify the metastatic prognosis of PCa cells and may serve as a useful biomarker or predictor of metastatic PCa. If our hypothesis is correct, then using carefully constructed, stable, non-toxic fluorescent ligands for the receptors, the number of 'hot' cells can be determined in a biopsy by clinicians/uropathologists to monitor the efficacy of anticancer therapy which the individual is undergoing and gauge the potential/progression to aggressive PCa. These results present both $\alpha_{1}$-ARs and GPR55 and catecholamines as potentially significant targets for specific therapeutic modalities for treating PCa.

\section{Conclusion}

The present study suggested an interaction between $\alpha_{1}$-AR and GPR55 via co-localization/dimerization providing rationale for further studies on mechanisms of cross talk between different subfamilies of GPCRs. These results open a new avenue of research oriented on delineating direct physical and functional interactions between the cannabinoid and adrenergic systems that were primarily attributed to only CB1 receptor mediated presynaptic inhibition of noradrenergic transmission [37]-[40]. We suggest, therefore, in the light of our findings and the wide, overlapping distribution of $\alpha_{1}$-AR and GPR55, re-evaluation of interactions between adrenergic and GPR55 systems in cells and tissues that co-express both using higher resolution techniques with fluorescent ligands. In addition, our finding that the $\alpha_{1}$-AR antagonist doxazosin alters GPR55 receptor number in cells endogenously expressing both $\alpha_{1}$-AR and GPR55 needs to be studied in vivo due to the potential clinical significance of doxazosin in suppressing prostate tumourigenicity [6]. The recent observation that GPR55 is expressed in PCa cell line [41], suggests that some of the anti-tumor effects of $\alpha_{1}$-AR antagonist [6] may be the result of indirect action on GPR55 in addition to the blockade of $\alpha_{1}$-AR. However, the unexpected, novel "GPR55" phenomenon finding, possibly conferring the properties of tumor growth and drug resistance, demonstrates the significant impact of $\alpha_{1}$-AR antagonists, particularly, doxazosin, in prostate carcinogenesis. To our knowledge, the current study in PC-3 cells is the first demonstration that chronic doxazosin treatment affects GPR55 expression. Since GPR55 has emerged as a lipid-sensitive modulator of oncogenesis, undoubtedly, pharmacology of LPIGPR55 autocrine signaling system warrants focused research to develop novel therapeutics targeting the protein or its ligand for the purposes of inhibiting cancer growth and limit the risk of metastases. Moreover, studies need to be designed to investigate any association between GPR55 expression and other membrane receptors as well as with cancer remission, relapse or resistance following treatment with various chemotherapeutic inhibitory agents.

\section{References}

[1] Russell, P.J. and Kingsley, E.A. (2003) Human Prostate Cancer Cell Lines. Methods in Molecular Medicine Prostate Cancer Methods and Protocols, 81, 21-39. http://dx.doi.org/10.1385/1-59259-372-0:21 
[2] Isaacs, J.T. (1994) The Role of Androgens in Prostatic Cancer. Vitamins \& Hormones, 49, 433-502. http://dx.doi.org/10.1016/S0083-6729(08)61152-8

[3] Crawford, E.D., Eisenberger, M.A., McLeod, D.C., Spaulding, J., Benson, R., Dorr, F.A., Blumenstein, B.A., Davis, M.A. and Goodman, P.J. (1989) A Controlled Randomized Trial of Leuprolide with and without Flutamide in Prostatic Cancer. New England Journal of Medicine, 321, 419-424. http://dx.doi.org/10.1056/NEJM198908173210702

[4] Daaka, Y.G. (2004) Proteins in Cancer: The Prostate Cancer Paradigm. Sci STKE, 216, 1-10.

[5] Hennenberg, M., Stief, C.G. and Gratzke, C. (2014) Prostatic a1-adrenoceptors: New Concepts of Function, Regulation, and Intracellular Signaling. Neurology \& Urodynamics, 33, 1074-1085. http://dx.doi.org/10.1002/nau.22467

[6] Kyprianou, N., Chon, J. and Benning, C.M. (2000) Effects of Alpha1-Adrenoceptor ( $\alpha_{1}$-AR) Antagonists on Cell Proliferation and Apoptosis in the Prostate: Therapeutic Implications in Prostatic Disease. The Prostate Supplement, 9, 42-46. http://dx.doi.org/10.1002/1097-0045(2000)45:9+<42::AID-PROS9>3.0.CO;2-U

[7] Desiniotis, A. and Kyprianou, N. (2011) Advances in the Design and Synthesis of Prazosin Derivatives over the Last Ten Years. Expert Opinion on Therapeutic Targets, 15, 1405-1418. http://dx.doi.org/10.1517/14728222.2011.641534

[8] Gray, K., Short, J. and Ventura, S. (2008) The $\alpha 1 \mathrm{~A}$-Adrenoceptor Gene Is Required for the $\alpha 1 \mathrm{~L}-$ Adrenoceptor-Mediated Response in Isolated Preparations of the Mouse Prostate. British Journal of Pharmacology, 155, 103-109. http://dx.doi.org/10.1038/bjp.2008.245

[9] Kyprianou, N., Litvak, J., Alexander, R.B., Borkowski, A. and Jacobs, S.C. (1998) Induction of Prostate Apoptosis by Doxazosin. Journal of Urology, 159, 1810-1815. http://dx.doi.org/10.1016/S0022-5347(01)63162-8

[10] Chon, J., Isaacs, J.T., Borkowski, A., Partin, A.W., Jacobs, S.C. and Kyprianou, N. (1999) $\alpha-1$ Adrenoceptor Antagonists Terazosin and Doxazosin Induce Prostate Apoptosis without Affecting Cell Proliferation in Patients with Benign Prostatic Hyperplasia. Journal of Urology, 161, 2002-2008. http://dx.doi.org/10.1016/S0022-5347(05)68873-8

[11] Harris, A.M., Warner, B.W., Wilson, J.M., Becker, A., Rowland, R.G., Conner, W., Lane, M., Kimbler, K., Durbin, E.B., Baron, A.T. and Kyprianou, N. (2007) Effect of $\alpha_{1}$-Adrenoceptor Antagonist Exposure on Prostate Cancer Incidence: An Observational Cohort Study. The Journal of Urology, 178, 2176-2180. http://dx.doi.org/10.1016/j.juro.2007.06.043

[12] Kyprianou, N. (2003) Doxazosin and Terazosin Suppress Prostate Growth by Inducing Apoptosis: Clinical Significance. The Journal of Urology, 169, 1520-1525. http://dx.doi.org/10.1097/01.ju.0000033280.29453.72

[13] Walden, P.D., Globina, Y. and Nieder, A. (2004) Induction of Anoikis by Doxazosin in Prostate Cancer Cells Is Associated with Activation of Caspase-3 and a Reduction of Focal Adhesion Kinase. Urological Research, 32, 261-265. http://dx.doi.org/10.1007/s00240-003-0365-7

[14] Garrison, J. and Kyprianou, N. (2006) Doxazosin Induces Apoptosis of Benign and Malignant Prostate Cells via a Death Receptor-Mediated Pathway. Cancer Research, 66, 464-472. http://dx.doi.org/10.1158/0008-5472.CAN-05-2039

[15] Henstridge, C.M. (2012) Off-Target Cannabinoid Effects Mediated by GPR55. Pharmacology, 89, 179-187. http://dx.doi.org/10.1159/000336872

[16] Chung, S.C., Hammarsten, P., Josefsson, A., Stattin, P., Granfors, T. and Egevad, L. (2009) A High Cannabinoid CB Receptor Immune-Reactivity Is Associated with Disease Severity and Outcome in Prostate Cancer. European Journal of Cancer, 45, 174-182. http://dx.doi.org/10.1016/j.ejca.2008.10.010

[17] Melck, D., Rueda, D., Galve-Roperh, I., De Petrocellis, L., Guzmán, M. and Di Marzo, V. (1999) Involvement of the cAMP/Protein Kinase A Pathway and of Mitogen-Activated Protein Kinase in the Anti-Proliferative Effects of Anandamide in Human Breast Cancer Cells. FEBS Letters, 463, 235-240. http://dx.doi.org/10.1016/S0014-5793(99)01639-7

[18] Sánchez, M.G., Ruiz-Llorente, L., Sánchez, A.M. and Díaz-Laviada, I. (2003) Activation of Phosphoinositide 3-Kinase/PKB Pathway by $\mathrm{CB}_{1}$ and $\mathrm{CB}_{2}$ Cannabinoid Receptors Expressed in Prostate PC-3 Cells: Involvement in Raf-1 Stimulation and NGF Induction. Cellular Signalling, 15, 851-859. http://dx.doi.org/10.1016/S0898-6568(03)00036-6

[19] Nithipatikom, K., Endsley, M.P., Isbell, M.A., Falck, J.R., Iwamoto, Y., Hillard, C.J. and Campbell, W. (2004) 2-Arachidonoylglycerol: A Novel Inhibitor of Androgen-Independent Prostate Cancer Cell Invasion. Cancer Research, 64, 8826-8830. http://dx.doi.org/10.1158/0008-5472.CAN-04-3136

[20] Sarfaraz, S., Afaq, F., Adhami, V.M. and Mukhtar, H. (2005) Cannabinoid Receptor as a Novel Target for the Treatment of Prostate Cancer. Cancer Research, 65, 1635-1641. http://dx.doi.org/10.1158/0008-5472.CAN-04-3410

[21] Brown, I., Cascio, M.G., Wahle, K.W., Smoum, R., Mechoulam, R. and Ross, R.A. (2010) Cannabinoid Receptor-Dependent and -Independent Anti-Proliferative Effects of Omega-3 Ethanolamides in Androgen Receptor-Positive and -Negative Prostate Cancer Cell Lines. Carcinogenesis, 31, 1584-1591. http://dx.doi.org/10.1093/carcin/bgq151

[22] Andradas, C., Caffarel, M.M., Perez-Gomez, E., Salazar, M., Lorente, M., Velasco, G., Guzman, M. and Sanchez, M. 
(2011) The Orphan G Protein-Coupled Receptor GPR55 Promotes Cancer Cell Proliferation via ERK. Oncogene, 30, 245-252. http://dx.doi.org/10.1038/onc.2010.402

[23] Bondarenko, A., Waldeck-Weiermair, M., Naghdi, S., Poteser, M., Malli, R. and Graier, W. (2010) GPR55-Dependent and -Independent Ion Signaling in Response to Lysophosphatidylinositol in Endothelial Cells. British Journal of Pharmacology, 161, 308-320. http://dx.doi.org/10.1111/j.1476-5381.2010.00744.X

[24] Daly, C.J., Ross, R.A., Whyte, J., Henstridge, C.M., Irving, A.J. and McGrath, J.C. (2010) Fluorescent Ligand Binding Reveals Heterogeneous Distribution of Adrenoceptors and “Cannabinoid-Like” Receptors in Small Arteries. British Journal of Pharmacology, 159, 787-796. http://dx.doi.org/10.1111/j.1476-5381.2009.00608.x

[25] Daly, C.J., Milligan, C.M., Milligan, G., Mackenzie, J.F. and Mcgrath, J.C. (1998) Cellular Localization and Pharmacological Characterization of Functioning Alpha-1 Adrenoceptors by Fluorescent Ligand Binding and Image Analysis Reveals Identical Binding Properties of Clustered and Diffuse Populations of Receptors. The Journal of Pharmacology and Experimental Therapeutics, 286, 984-990.

[26] Hudson, B.D., Hébert, T.E. and Kelly, M. (2010) Physical and Functional Interactions between CB $_{1}$ Cannabinoid Receptors and $\beta 2$-Adrenocepors. British Journal of Pharmacology, 160, 627-642. http://dx.doi.org/10.1111/j.1476-5381.2010.00681.x

[27] Daly, C.J. and McGrath, J.C. (2011) Previously Unsuspected Widespread Cellular and Tissue Distribution of Beta-Adrenoceptors and Its Relevance to Drug Action. Trends in Pharmacological Sciences, 32, 219-226. http://dx.doi.org/10.1016/j.tips.2011.02.008

[28] Angers, S., Salapour, A. and Bouvier, M. (2002) Dimerization: An Emerging Concept for G Protein-Coupled Receptor Ontogeny and Function. Annual Review of Pharmacology and Toxicology, 42, 409-435. http://dx.doi.org/10.1146/annurev.pharmtox.42.091701.082314

[29] Milligan, G., Pediani, J., Fidock, M. and López-Giménez, J.F. (2004) Dimerization of Alpha1-Adrenoceptors. Biochemical Society Transactions, 32, 847-850.

[30] Uberti, M., Hague, C., Oller, H., Minneman, K. and Hall, R. (2005) Heterodimerisation with $\beta_{2}$-Adrenergic Receptors Promotes Surface Expression and Functional Activity of $\alpha_{1 \mathrm{D}}$-Adrenergic Receptors. Journal of Pharmacology and Experimental Therapeutics, 313, 16-23. http://dx.doi.org/10.1124/jpet.104.079541

[31] Copik, A.J., Ma, C., Kosaka, A., Sahdeo, S., Trane, A., Ho, H., Dietrich, P.S., Yu, H., Ford, A.P., Button, D. and Milla, M.E. (2009) Facilitatory Interplay in $\alpha_{1 \mathrm{a}}$ and $\beta_{2}$ Adrenoceptor Function Reveals a Non-Gq Signaling Mode: Implications for Diversification of Intracellular Signal Transduction. Molecular Pharmacology, 75, 713-728. http://dx.doi.org/10.1124/mol.108.050765

[32] Pennefather, J.N., Lau, W.A., Mitchelson, F. and Ventura, S. (2000) The Autonomic and Sensory Innervation of the Smooth Muscle of the Prostate Gland: A Review of Pharmacological and Histological Studies. Journal of Autonomic Pharmacology, 20, 193-206. http://dx.doi.org/10.1046/j.1365-2680.2000.00195.X

[33] Aarons, R.D., Nies, A.S., Gal, J., Hegstrand, L.R. and Molinoff, P.B. (1980) Elevation of Beta-Adrenergic Receptor Density in Human Lymphocytes after Propranolol Administration. Journal of Clinical Investigation, 65, 949-957. http://dx.doi.org/10.1172/JCI109781

[34] Foster Jr., H.E., Yono, M., Shin, D., Takahashi, W., Pouresmail, M., Afiatpour, P. and Latifpour, J. (2004) Effects of Chronic Administration of Doxazosin on $\alpha_{1}$-Adrenoceptors in the Rat Prostate. The Journal of Urology, 172, 24652470. http://dx.doi.org/10.1097/01.ju.0000138475.89790.88

[35] Yono, M., Poster Jr., H.E., Shin, D., Takahashi, W., Pouresmail, M. and Latifpour, J. (2004) Doxazosin Treatment Causes Differential Alterations of $\alpha_{1}$-Adrenoceptor Subtypes in the Rat Kidney, Heart and Aorta. Life Sciences, 75, 2605-2614. http://dx.doi.org/10.1016/j.lfs.2004.08.001

[36] Kreda, S.M., Sumner, M., Fillo, S., Ribeiro, C.M., Luo, G.X., Xie, W., Daniel, K.W., Shears, S., Collins, S. and Wetsel, W.C. (2001) $\alpha_{1}$-Adrenergic Receptors Mediate LH-Releasing Hormone Secretion through Phospholipases C and $A_{2}$ in Immortalized Hypothalamic Neurons. Endocrinology, 142, 4839-4851.

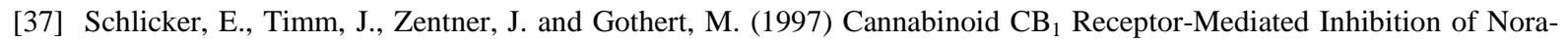
drenaline Release in the Human and Guinea-Pig Hippocampus. Naunyn-Schmiedeberg's Archives of Pharmacology, 356, 583-589. http://dx.doi.org/10.1007/PL00005093

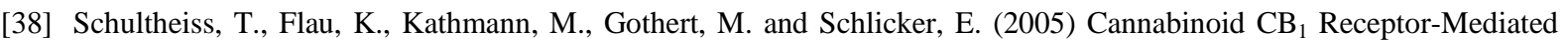
Inhibition of Noradrenaline Release in Guinea-Pig Vessels, but Not in Rat and Mouse Aorta. Naunyn-Schmiedeberg's Archives of Pharmacology, 372, 139-146. http://dx.doi.org/10.1007/s00210-005-0007-4

[39] Pakdeechote, P., Dunn, W.R. and Ralevic, V. (2007) Cannabinoids Inhibit Noradrenergic and Purinergic Sympathetic Cotransmission in the Rat Isolated Mesenteric Arterial Bed. British Journal of Pharmacology, 152, 725-733. http://dx.doi.org/10.1038/sj.bjp.0707397

[40] Tam, J., Trembovler, V., Di Marzo, V., Petrosino, S., Leo, G., Alexandrovich, A., Regev, E., Casap, N., Shteyer, A., 
Ledent, C., Karsak, M., Zimmer, A., Mechoulam, R., Yirmiya, R., Shohami, E. and Bab, I. (2008) The Cannabinoid $\mathrm{CB}_{1}$ Receptor Regulates Bone Formation by Modulating Adrenergic Signaling. The FASEB Journal, 22, 285-294. http://dx.doi.org/10.1096/fj.06-7957com

[41] Pineiro, R., Maffucci, T. and Falasca, M. (2011) The Putative Cannabinoid Receptor GPR55 Defines a Novel Autocrine Loop in Cancer Cell Proliferation. Oncogene, 30, 142-152. http://dx.doi.org/10.1038/onc.2010.417 